\title{
Exogenous lipid pneumonia: a retrospective multicentre study of 44 cases in France
}

\author{
A. Gondouin*, Ph. Manzoni**, E. Ranfaing ${ }^{+}$, J. Brun ${ }^{++}$, J. Cadranel\#, \\ D. Sadoun\#\#, J.F. Cordier $¥$, A. Depierre*, J.C. Dalphin*
}

Exogenous lipid pneumonia: a retrospective multicentre study of 44 cases in France. A. Gondouin, Ph. Manzoni, E. Ranfaing, J. Brun, J. Cadranel, D. Sadoun, J.F. Cordier, A. Depierre, J.C. Dalphin. [ERS Journals Ltd 1996.

ABSTRACT: A nationwide retrospective study of exogenous lipid pneumonia (ELP) was carried out to update the data on this disease, with emphasis on thoracic computed tomography (CT) scan and bronchoalveolar lavage (BAL) findings.

The inclusion criteria were: 1) presence of abnormal imaging features compatible with the diagnosis of ELP; 2) presence of intrapulmonary lipids; and 3) exogenous origin of the lipid pneumonia.

Forty four cases were included ( 20 males and 24 females; mean age 62 \pm 11 yrs), of which four were occupational (chronic inhalation of cutting mist or oily vapour in an industrial environment). Thirty of the $\mathbf{4 0}$ nonoccupational cases were related to aspiration of liquid paraffin used for the treatment of constipation. A condition possibly favouring oil aspiration or inhalation was present in 34 patients $(77 \%)$, most commonly gastro-oesophageal reflux $(n=20)$ and neurological or psychiatric illness $(n=14)$. Fever $(39 \%)$, weight loss $(34 \%)$, cough $(64 \%)$, dyspnoea $(50 \%)$ and crepitations $(45 \%)$ were the most frequent symptoms. BAL was performed in 39 cases: $23 \%$ had a lymphocytic alveolitis; $14 \%$ neutrophilic alveolitis; and $31 \%$ a mixed alveolitis (lymphocytic and neutrophilic). Alveolar consolidations $(57 \%)$, ground glass opacities $(39 \%)$, and alveolar nodules $(23 \%)$ were the most common radiological abnormalities. The changes were bilateral $(79 \%)$, predominant in the posterior and lower zones of the lobes concerned $(74 \%)$, hypodense ( $71 \%)$, and spared the subpleural zones $(52 \%)$. In 13 cases, hypodensity was retrospectively established on CT scan by the presence of a "positive angiogram". This sign may be of diagnostic value when the density measurement is either not possible or not reliable.

In conclusion, this study provides an update of the clinical, biological and radiological profile of exogenous lipid pneumonia and, in particular, confirms the diagnostic benefit of computed tomography scan, which revealed bilateral and hypodense changes in a large majority of cases.

Eur Respir J., 1996, 9, 1463-1469.

Exogenous lipid pneumonia (ELP) is an uncommon condition resulting from the aspiration or inhalation of fatlike material of animal, vegetable or mineral origin. Most cases of ELP occur from mineral oil, a mixture of inert, long-chain, saturated hydrocarbons obtained from petroleum. Mineral oils can inhibit the cough reflex and ciliary motility, thus facilitating inhalation. Their presence in the pulmonary parenchyma is responsible for a foreign body type of inflammatory reaction [1-3]. The aspiration of milk, olive oil, cod liver oil, and especially paraffin oil, used as a laxative or less frequently in nasal drops, has long been known to be a cause of ELP. Occasionally, the disease has been caused by using poppy seed oil as a bronchography medium. Numerous other conditions, recently reviewed [4] are also possible. Mineral oils, used in industry as lubricants and cutting fluids in either fluid or spray form, for turning, milling and grinding operations [5], are another major cause of ELP.

ELP must be distinguished from "endogenous" lipid pneumonia, sometimes called "cholesterol" pneumonia, which usually develops when lipids that normally reside
Depts of *Respiratory Disease, **Radiology, and +Pathology, University Hospita of Besançon, France. ${ }^{++}$Dept of Respiratory Disease, University Hospital of Caen, France. \#Dept of Respiratory Disease, Tenon University Hospital, Paris, France. \#Dept of Respiratory Disease, University Hospital of Bobigny, France. ‡Dept of Respiratory Disease and GERM'O'P, University Hospital of Lyon, Lyon, France.

Correspondence: J.C. Dalphin

Dept of Respiratory Disease

CHR of Besançon

2 place St Jacques

25000 Besançon

France

Keywords: Bronchoalveolar lavage

exogenous lipid pneumonia

paraffin pneumonia

thoracic computed tomography

Received: June 21995

Accepted after revision February 121996 in the lung tissue escape from destroyed alveolar cell walls (e.g. obstructive airway lesion, suppurative process) [5]. Endogenous lipids can sometimes appear in the lung with fat emboli, pulmonary alveolar proteinosis, and lipid storage disorders [6]. Medical history, microscopic findings and fat stains can distinguish ELP from endogenous lipid pneumonia [4].

The exact frequency of ELP is difficult to establish. In autopsy series, it varies from 1 to 2.5\% [7]. In 1976, Rouffy et al. [7] analysed 81 cases published from 1941 to 1975 . We decided to conduct a national retrospective study in order to update the data concerning this disease, including thoracic computed tomography (CT) scan and bronchoalveolar lavage (BAL).

\section{Methods}

Cases were collected in a national retrospective survey conducted between August 1992 and June 1993. A questionnaire was sent to French respiratory medicine departments (210 letters). Participants were to return the 
questionnaire along with histological and radiological documents (chest radiograph, anteroposterior (AP) and lateral, thoracic CT scan).

The inclusion criteria for cases of ELP were as follows, according to SPICKARD and HIRSCHMANN [4]: 1) presence of an abnormal pulmonary image, compatible with the diagnosis of ELP according to data in the literature; 2) presence of intrapulmonary lipids, proven by histological examination or BAL (presence of optically empty vacuoles, either free or inside macrophages, suggestive of lipid vacuoles, possibly confirmed by a specific fat stain); and 3) evidence of the exogenous origin of the lipid pneumonia, provided either by clinical interview or by identification of oil by biochemical analysis (thin layer silica gel chromatography or infrared spectrophotometry). If evidence of exposure was not found, the diagnosis was retained in the absence of any clinical, laboratory or radiological features of endogenous lipid pneumonia.

Radiological documents were interpreted independently by two readers: a respiratory physician (JCD) and a radiologist (PhM).

Radiological images were described using the terminology recommended by the "Société Française d'Imagerie Thoracique" and the "Club Thorax" [8], and by the nomenclature committee of the Fleischner Society [9].

\section{Results}

\section{Population}

Forty four cases in which diagnosis of ELP was established between 1981 and 1993 were included: 24 females and 20 males, mean age 62 \pm 11 yrs (range 36-87 yrs). The diagnosis of lipid pneumonia was based on BAL in 18 cases, pulmonary histology or cytology in 16 cases, and a combination of the two methods in 10 cases. Proof of the exogenous origin was obtained by clinical interview in 36 cases, and by formal identification (chromatography or spectrophotometry) in seven cases. In one case, the origin of the oil was not elucidated, but there were no arguments in favour of endogenous lipid pneumonia.

\section{Aetiological circumstances}

The majority of cases were not related to occupational exposure (table 1). The commonest aetiology was the administration of liquid paraffin for the treatment of chronic constipation. Liquid paraffin was aspirated either spontaneously or was facilitated by the presence of gastro-oesophageal reflux, a psychiatric illness or a dose at bedtime. The duration of exposure was generally long (mean $9.5 \mathrm{yrs}$ ), but sometimes brief (one case after 1 month of treatment with liquid paraffin). There were four occupational cases due to chronic inhalation of cutting mist or oily vapour either in a metallurgic plant (three cases) or a cable factory (one case).

\section{Clinical presentation and concomitant diseases}

The commonest symptoms were fever (39\%), weight loss (34\%), cough (64\%), dyspnoea (50\%), and crackles
Table 1. - Aetiological circumstances

\begin{tabular}{lrr}
\hline & $\mathrm{n}$ & $\%$ \\
\hline Occupational & 4 & 9 \\
Nonoccupational & 40 & 91 \\
Conditions responsible for oil consumption & & \\
$\quad$ Constipation & 32 & 80 \\
$\quad$ Rhinitis (nasal instillation) & 7 & 18 \\
$\quad$ Amateur singer (buccal instillation) & 1 & 3 \\
Factors predisposing to oil consumption & & \\
$\quad$ Gastro-oesophageal reflux & 20 & 50 \\
$\quad$ Psychiatric illness & 14 & 38 \\
Administration at bedtime & 13 & 33 \\
$\quad$ Neurological disease & 3 & 8 \\
$\quad$ ENT disease & 2 & 5 \\
$\quad$ Other* & 2 & 5 \\
$\quad$ None & 10 & 25 \\
Nature of oil & & \\
$\quad$ Liquid paraffin & 30 & 75 \\
$\quad$ Vaseline & 5 & 13 \\
$\quad$ Other & 5 & 13 \\
\hline
\end{tabular}

*: achalasia (one case) and oesophageal diverticulum (one case) without proven reflux. ENT: ear, nose and throat.

(45\%) (table 2). Three cases were associated with primary lung cancers (two squamous carcinomas and one adenocarcinoma) arising in smokers and located away from the site of lipid pneumonia. Six patients had superinfections, due to common organisms in four cases and to mycobacteria in two cases.

\section{Laboratory tests}

The erythrocyte sedimentation rate (measured in 36 cases) was greater than $20 \mathrm{~mm} \cdot \mathrm{h}^{-1}$ in $61 \%$ of cases. Leucocytosis $\left(>10 \infty 10^{9}\right.$ cells $\left.\cdot \mathrm{L}^{-1}\right)$ was present in $22 \%$ of cases, with a predominance of neutrophil polymorphonuclear cells in all cases, and it was associated with bronchial infections in three cases.

\section{Lung function tests}

Twenty four patients underwent lung function tests. A restrictive ventilatory syndrome (total lung capacity (TLC) $<80 \%$ predicted) was observed in $39 \%$ of cases, an obstructive ventilatory syndrome (forced expiratory

Table 2. - Clinical presentation

\begin{tabular}{lrr}
\hline & $\mathrm{n}$ & $\%$ \\
\hline Circumstances of discovery & & \\
Incidental & 18 & 41 \\
Symptoms & 26 & 59 \\
General signs & 26 & 59 \\
Fever & 17 & 39 \\
Weight loss & 15 & 34 \\
Pulmonary symptoms & 33 & 75 \\
Cough & 28 & 64 \\
Dyspnoea & 22 & 50 \\
Sputum & 12 & 28 \\
Chest pain & 9 & 21 \\
Haemoptysis & 6 & 13 \\
Physical signs & 27 & 62 \\
Crackles & 20 & 45 \\
Bronchial rales & 3 & 7 \\
Finger clubbing & 1 & 3 \\
\hline
\end{tabular}


Table 3. - Imaging features

\begin{tabular}{lcc}
\hline & $\mathrm{n}$ & $\%$ \\
\hline Type of images (n=44) & & \\
Alveolar consolidations & 25 & 57 \\
Ground glass opacities & 17 & 39 \\
Alveolar nodules & 10 & 23 \\
Pseudotumoral consolidations & 6 & 14 \\
Linear opacities & 6 & 14 \\
Mediastinal adenopathies & 4 & 9 \\
Cavitary images & 2 & 5 \\
Pleural effusions & 2 & 5 \\
Sites of opacities (n=38)* & & \\
Bilateral involvement & 30 & 79 \\
Right lung & 34 & 89 \\
$\quad$ Upper lobe & 15 & 39 \\
$\quad$ Middle lobe & 31 & 89 \\
$\quad$ Lower lobe & 31 & 82 \\
Left lung & 36 & 95 \\
$\quad$ Superior segment of upper lobe & 8 & 21 \\
$\quad$ Lingula & 18 & 47 \\
$\quad$ Lower lobe & 32 & 85 \\
CT scan appearances (n=31)** & & \\
Declivity & 23 & 74 \\
Low density (CT angiogram sign) & $22(13)$ & 71 \\
Sparing of the periphery & 16 & 52 \\
Retractile nature & 7 & 23 \\
\hline
\end{tabular}

*: six cases only had an anteroposterior (AP) chest radiograph; **: the nature of images was evaluated on 31 CT scans. CT: computed tomography; declivity: predominant in the posterior and lower zones of the lobes concerned.

volume in one second/vital capacity (FEV1/VC) $<75 \%)$ in $28 \%$ of cases, and a mixed syndrome in $8 \%$ of cases. The transfer factor for carbon monoxide, determined in 16 cases, was less than $80 \%$ of predicted in $63 \%$ of cases.

\section{Imaging features}

Forty four standard chest radiographs and $31 \mathrm{CT}$ scans considered to be of satisfactory quality were analysed (table 3). The site of the images was assessed in 38 cases with an AP and lateral chest radiograph. Representative examples of the predominant features are shown in figures 1-6. Alveolar consolidations (figs. 1, 3 and 6) and

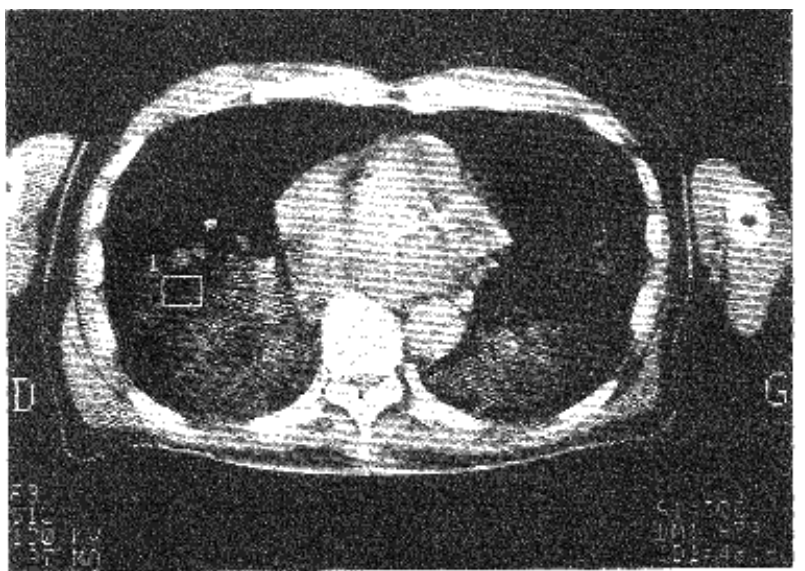

Fig. 1. - Declivitous (i.e. predominant in the posterior and lower zones of the lobes concerned), bilateral alveolar consolidations. Hypodensity measured at -79 Hounsfield units and observed by comparison with subcutaneous adipose tissue. Sparing of the periphery. ground glass opacities (fig. 2) were the most frequent images. In 30 out of 38 cases, the images were bilateral, with a marked predominance for the lower lobes. Declivity (i.e. predominance in posterior and lower zones of the lobes concerned) (fig. 4) and hypodensity were the usual features. Hypodense images were assessed by density measurements (in Hounsfield units (HU)), or by visual comparison with subcutaneous adipose tissue (fig. 1), or by the "angiogram sign" (figs. 3, 5 and 6), on parenchymal window setting. The latter sign consists of visualization of normally branching pulmonary vessels

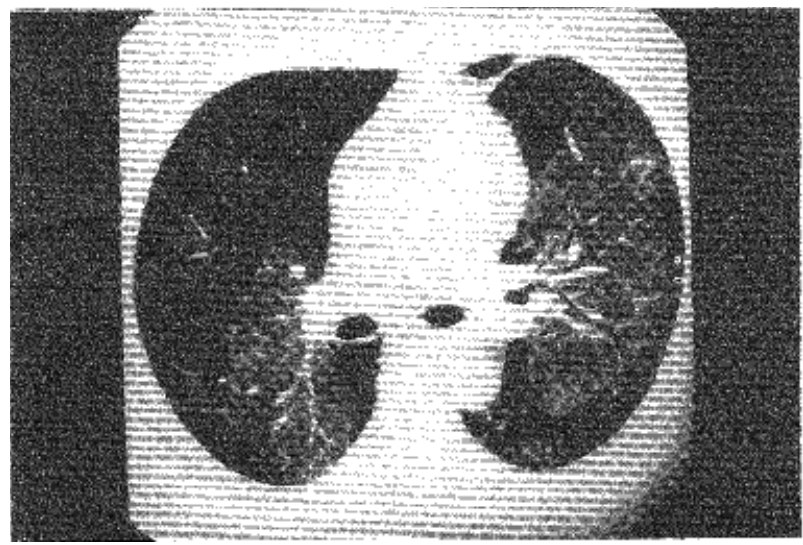

Fig. 2. - Bilateral ground glass opacities. Sparing of the periphery.

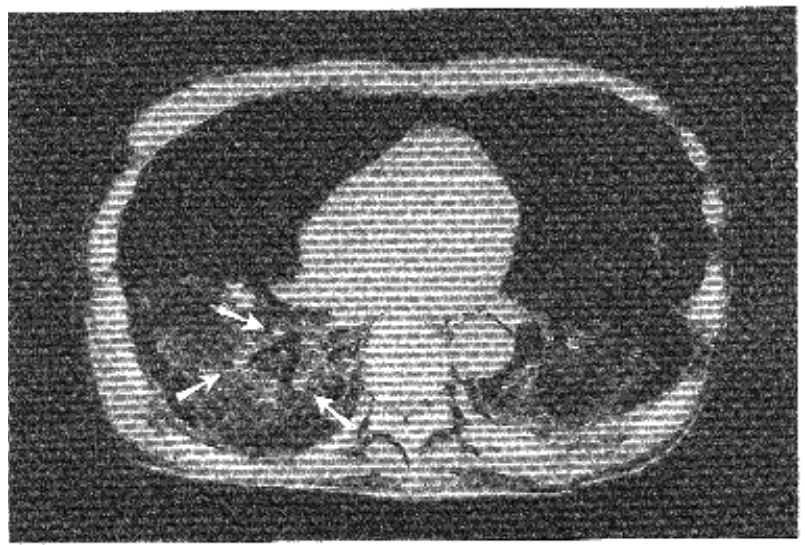

Fig. 3. - Bilateral alveolar consolidations. On the right, the air bronchogram is surrounded by three cross-sectioned angiograms (arrows).

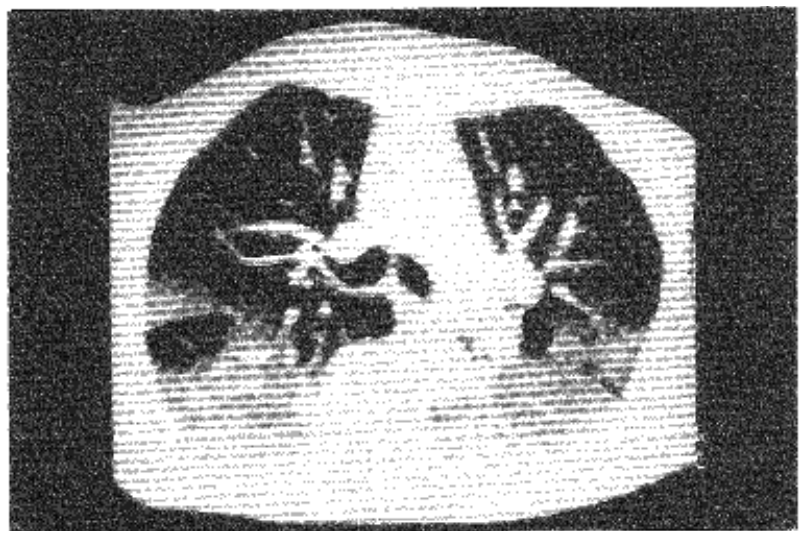

Fig. 4. - Declivitous (i.e. predominant in the posterior and lower zones of the lobes concerned), bilateral images. Zone of "spared healthy lung" located under the right major fissure ("sandwich aspect"). 


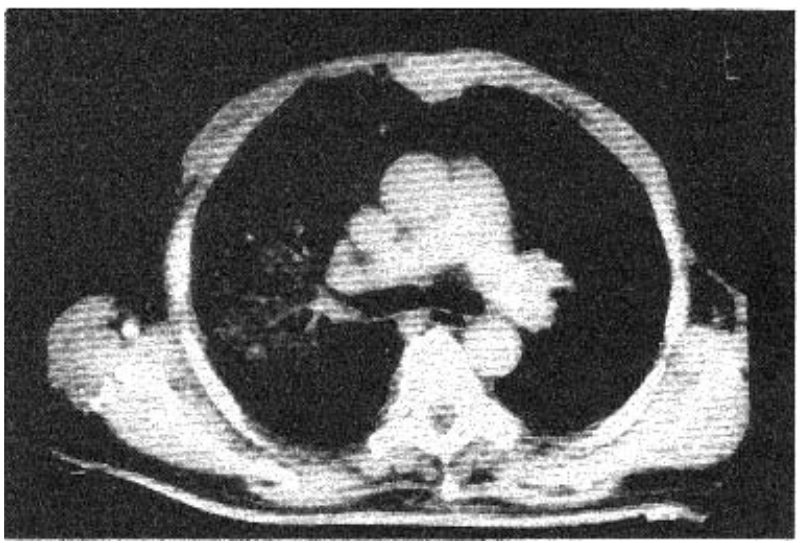

Fig. 5. - Longitudinal sectioned angiogram inside a conglomerate of alveolar nodules.

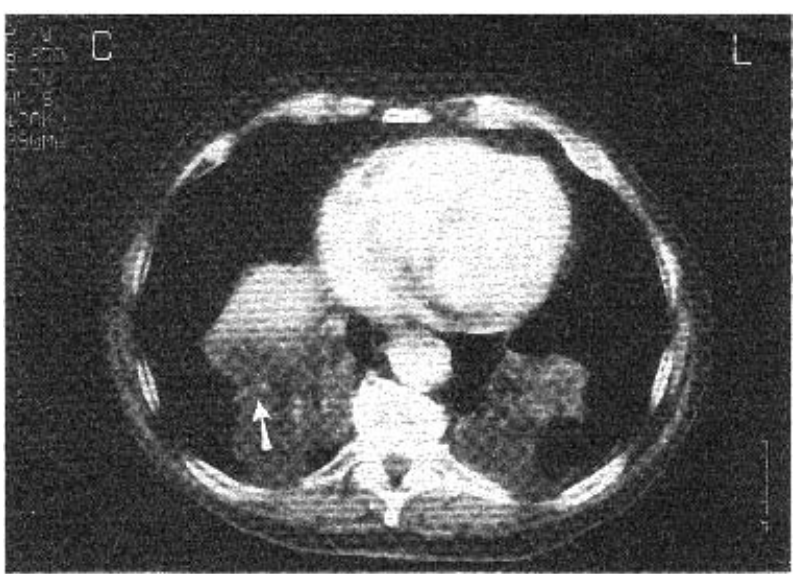

Fig. 6. - Bilateral alveolar consolidations. Normally branching angiogram (arrow). Several bilateral cross-sectioned angiograms.

within the consolidated lung on postcontrast CT. It was present in 13 cases, among which eight were non-contrast enhanced. In seven cases, the declivity of the images gave a "sandwich" appearance with a subfissural zone of healthy lung between two pathological zones (fig. 4). One of the two cavitary images was probably due to an atypical mycobacterial infection. In one case, a mediastinal adenopathy presented a very low density and was therefore, probably related to lipid pneumonia.

The four occupational cases consisted of diffuse interstitial forms, which were not predominant in the lower lobes: reticulonodular pattern (one case); ground glass appearance (one case); nodular pattern (one case); nodular and ground glass (one case).

\section{Fibreoptic bronchoscopy and BAL}

The BAL fluid appearance was abnormal (milky, oily or haemorrhagic) in $44 \%$ of cases (table 4 ). A lymphocytic alveolitis (defined by more than $20 \%$ lymphocytes at differential cell count) was present in $23 \%$ of cases. Neutrophilic alveolitis (defined by more than $5 \%$ neutrophils at differential cell count) was observed in 14\% of cases. The alveolitis was mixed, both lymphocytic and neutrophilic, in $31 \%$ of cases. Finally, in two cases, BAL eosinophilia was present (with 10 and $36 \%$ of eosinophils, respectively).
Table 4. - Endobronchial aspect and principal characteristics of the BAL

\begin{tabular}{lcc}
\hline & Number & $\%$ \\
\hline $\begin{array}{l}\text { Endobronchial aspect } \\
\text { Number of endoscopic examinations }\end{array}$ & 43 & \\
performed & & \\
$\quad$ Diffuse inflammatory aspect & 8 & 19 \\
$\quad$ Localized inflammatory aspect & 3 & 3 \\
$\quad$ Presence of secretions & 5 & 12 \\
$\quad$ Diffuse telangiectasias & 1 & 2 \\
$\quad$ Normal & 24 & 56 \\
$\quad$ Not specified & 2 & \\
Characteristics of BAL & & \\
Number of BAL performed & 39 & \\
Aspect & & \\
$\quad$ Oily or milky & 11 & 28 \\
$\quad$ Haemorrhagic & 6 & 15 \\
$\quad$ Normal or not specified & 22 & 57 \\
Cell count (n=35) & & \\
$\quad$ Number of cells:mm-3* & & $324 \pm 312$ \\
$\quad$ Percentage of lymphocytes* & & $22 \pm 16$ \\
$\quad$ Lymphocytes > 20\% & & 54 \\
$\quad$ Percentage of neutrophils* & & $14 \pm 19$ \\
$\quad$ Neutrophils >5\% & & 45 \\
\hline
\end{tabular}

*: mean \pm SD. BAL: bronchoalveolar lavage.

Thirty nine of the 44 patients underwent a BAL: lipophages with a characteristic appearance made diagnosis possible in 30 cases. Diagnosis was completed in 15 of these cases by specific fat stains, which were positive in all cases (either sudan black, sudan red or oil red O), and in seven cases by identifying the oil by spectrophotometry or chromatography, which in each case made it possible to show that the oil inhaled was the same as the intrapulmonary oil (paraffin in four cases, vaseline in one case, and cutting mist in two cases). This diagnosis was supported in 15 of the 30 cases with characteristic appearance on BAL by a histological examination. Of the nine other cases, whose BAL was not diagnostic, transbronchial biopsies were performed in eight patients and were positive in seven cases. In one case, a negative biopsy led to thoracotomy; a thoracotomy was the initial diagnostic procedure in one case. Five patients did not undergo BAL. In these five patients, diagnosis was reached by thoracotomy in four cases and transparietal puncture in one, but transbronchial biopsies had not been performed beforehand.

\section{Histological features}

Twenty four cases were submitted to histological examination: transbronchial biopsy in 14 cases, open lung biopsy in eight cases, thoracoscopic lung biopsy in one case, and bronchial biopsy in one case. The predominant lesion was fibrosis (14 cases), which was either exclusively interstitial (10 cases) or "mutilating" with a disorganization of the pulmonary architecture (four cases). The fibrotic tissue was infiltrated by optically empty vacuoles corresponding to lipids, which were both alveolar and interstitial, free and within macrophages. An inflammatory reaction was detected in 16 cases, with the appearance of a giant cell granuloma in 13 cases. 


\section{Treatment and clinical course}

Oil exposure was stopped in 37 cases. The therapeutic approaches included treatment of the predisposing factor leading to aspiration (usually gastro-oesophageal reflux) in 13 cases, corticosteroid therapy in six cases, therapeutic lung lavage in six cases, and in the other cases, treatments such as long-term oxygen therapy in a patient who had progressed to the stage of chronic respiratory failure, immediate resection of the lesion, secondary resection as a result of recurrent superinfection, and immunosuppressants following a course of corticosteroids.

The clinical and functional course was specified in 28 cases. The following outcomes were observed: 13 improvements (46\%); seven stable courses (25\%); six deteriorations or complications (21\%) (fibrosis, repeated episodes of infection in the territory of the lipid pneumonia, Aspergillus infestation with parenchymal excavation).

There were two deaths unrelated to the lipid pneumonia. Imaging follow-up was available for 21 cases and showed: three complete cures (14\%); six improvements (29\%); 10 stable courses (48\%); and two deteriorations $(10 \%)$. In the 32 cases in which the intoxication was discontinued and the course known, five patients deteriorated (despite corticosteroid therapy in one case), whilst the other 27 patients remained stable, improved, or were even cured, regardless of concomitant treatment (corticosteroids, therapeutic BAL or treatment of predisposing factors).

\section{Discussion}

The commonest aetiological circumstance was administration of liquid paraffin for the treatment of refractory constipation. The predominance of this aetiology is frequently reported in the literature but used to be less marked, and, in some cases, was of similar importance to nasal instillation of oily products for chronic rhinopharyngeal diseases $[2,7,10,11]$. The oil responsible was almost always a mineral oil (paraffin or vaseline). Two of the present cases were related to vegetable oils (peanut oil and olive oil included in nose drop formulae) which are reputed to be minimally toxic for the lung; however, one case developed a "paraffinoma", i.e. a dense lesion with a pseudotumoral appearance, associated with fibrosis of the pulmonary parenchyma. The long duration of exposure (mean of 9.5 yrs) concurs with other results in the literature $[2,7,10]$. One case occurred after administration of an oily substance for only 1 month. Several similar examples, in which the duration of the exposure ranged 1-3 months, were reported in the analysis of RoufFy et al. [7]. The predisposing factors identified have been reported in several papers [2, 10, 12, 13, 15, 16], but with no indication of their frequency. These predisposing factors are not obligatory for oil to penetrate into the airways, as they were absent in $25 \%$ of the present cases.

This series is the first to include an extensive study of CT scans, as most of the other publications reporting large series predate the development of the technology. The most frequent aspects were extensive and bilateral alveolar consolidations and ground glass opacities. It is difficult to compare the present results with those of older series, in which the terms used to describe the radiological images are sometimes no longer used ("plaques", "marbling"). However, in 1970, GeNEREux [6] reported a radiological description, which, although not providing precise data concerning the frequency of the various images, corresponded to the impression given by the present series. The author did not mention the ground glass opacities, but this aspect was reported by VoLK et al. [10]. The density of parenchymal lesions on CT scan can be measured during the examination, but the lesion would have to be homogeneous, as the presence of air inside the lesions would give falsely negative measurements. A negative density (between -150 and $-30 \mathrm{HU}$ ) is highly suggestive of the presence of intrapulmonary fat [17-19]. In this series, a low-density lesion was detected in only five cases; in contrast, in 13 cases, the low density was established retrospectively by the presence of a positive angiogram within alveolar consolidations (12 cases) or conglomerates of nodular images (one case) (fig. 5). This sign seems to have an interesting diagnostic value as a complement to density measurement, when this measurement cannot be reliably performed. For Iм et al. [20] the presence of a CT angiogram sign requires two factors. One is that the consolidated lung should present a considerably lower attenuation than the enhancing vessels, and the other is that the arrangement of vascular trees should not be significantly distorted by the pathological process (fig. 6). ELP fulfils these conditions. This sign has previously been described in lobar bronchioloalveolar carcinoma and may also be present in pulmonary oedema, caused by increased hydrostatic pressure or acute pulmonary infarction [20].

The present results concerning the site of the lesions differ from those reported previously. The radiological images were much more frequently bilateral (79\%) and affected left and right lungs almost equally (95 and 89\%). They were often multilobar and, in particular, quadrilobar. In contrast, in the studies by GENEVRIER [14], EVEN et al. [11], RoufFy et al. [7], and Wright and JEFFREY [13], lesions were described as being more often unilateral and predominantly affecting the right side, as in classical inhalation pneumonia. This difference may be explained by the fact that CT examinations demonstrated images not visible on chest radiographs. We feel that CT scan, therefore, makes a major contribution to the diagnosis of ELP. It provides an exact assessment of the lesion and, in particular, demonstrates the low density of the images and their declivity. The four occupational cases consisted of diffuse interstitial forms. The sizes of inhaled particulates in these forms are smaller than in the other forms; this might explain the radiological aspect of the pneumopathy.

The appearance of BAL was highly suggestive (oily) in almost $20 \%$ of cases and this may immediately suggest the diagnosis. Cytological analysis showed a high mean cellularity in the present series ( 324 cells $\cdot \mathrm{mm}^{-3}$ ). CORWIN and IRWIN [21] reported a similar finding on BAL of nine subjects, but LAUQUE et al. [22] reported normal cellularity. Various cytological profiles have been described in the literature for isolated cases: macrophage alveolitis [23-25); lymphocytic alveolitis [26-28], and neutrophilic alveolitis [22]. Study of the 35 cases submitted to BAL with cytological analysis provides an idea of the frequency of these cytological profiles: normal (31\% 
cases); isolated lymphocytic (23\%); isolated neutrophilic (14\%); and mixed alveolitis (31\%). No cytological profile is, therefore, more particularly suggestive of this disease.

Both BAL and transbronchial biopsy contributed significantly to diagnosis. Diagnosis was reached in 30 of the 39 BAL performed (77\%). In the nine remaining cases, transbronchial biopsy made diagnosis possible in eight cases, and in one case, negative transbronchial biopsies led to thoracotomy. In the five cases where diagnosis was obtained by thoracotomy or transthoracic needle biopsy (one case), had BAL or transbronchial biopsy been performed beforehand, these invasive techniques could probably have been avoided, notably in view of the above results.

Histological examination revealed two important points: the frequency of the granulomatous form of the inflammatory cell reaction (13 cases) suggesting a foreign body disease; and the frequency of fibrotic lesions (14 cases), which explains the potential severity of the disease with a possibility of progression to fibrosis with disorganization of the pulmonary architecture (four cases) and chronic respiratory failure.

The clinical presentation was not very different from that reported in the literature. The latent nature of the disease is classic: $41 \%$ of cases in this series were incidental findings, among which $25 \%$ of cases remained effectively latent. Fever (39\%), weight loss (34\%), cough (64\%) and dyspnoea (50\%) were the most frequent findings.

The respiratory function characteristics of ELP have seldom been reported. The present series confirms the functional profile reported elsewhere in isolated cases, i.e. normal respiratory function or restrictive ventilatory syndrome. Transfer factor for carbon monoxide was measured in 16 cases and was frequently abnormal (63\% of cases). Obstructive ventilatory syndrome was also detected (seven cases, including five in smoking patients)

The therapeutic approach most frequently adopted was discontinuation of the oil exposure (37 cases). Both in this series and in the literature, corticosteroids and therapeutic BAL have not been demonstrated to be really effective and cannot be proposed as the treatment for all cases. Surgery is seldom required in the treatment of ELP. One patient underwent a lobectomy to treat recurrent infection in the area of the lipid pneumonia. Finally, the predisposing factors are not always treated (13 cases in this series; whilst gastro-oesophageal reflux, which is amenable to treatment, was present in 20 cases). However, such treatment would appear to be justified, as the advice to stop using the oily substance may not always be followed by patients who are very often dependent on their treatment.

In conclusion, the frequently misleading appearance of exogenous lipid pneumonia with clinical signs (cough, dyspnoea, fever, diaphoresis) and radiological signs (alveolar consolidations, ground glass opacities) can suggest an infectious, neoplastic or immunoallergic disease. It is, therefore, important to consider the possibility of lipid pneumonia, which can be very strongly suspected at computed tomography scan by the presence of bilateral, declivitous, hypodense images, which may be notably detected by the angiogram sign. When a lipid pneumonia is suspected, bronchoalveolar lavage completed by transbronchial biopsies, leads to diagnosis in the vast majority of cases. Open lung biopsy and even thoracoscopy should therefore become the exception in this disease.

Acknowledgements: The authors thank the following clinicians who participated in the study on exogenous lipid pneumonia by contributing one or two patients: J. Aerts, P. Cacoub, M.F. Carette, T. François, B. Dautzenberg, P. Lher (Paris); B. Adriananja (Meaux); D. Anthoine, F. Chabot (Nancy); O. Benezet (Nîmes); J.P.D. Bernard, J.C. Guerin (Lyon); F. Blanc-Jouvan (Grenoble); J.L. Breton (Belfort); J.C. Cheminat (Clermont-Ferrand); T. Dolige (Beauvais); O. Faux (Chatellerault); P. Foucher (Dijon); J.P. Gaillard (Dieppe); P. Guibout (Versailles); F. Lebargy (Créteil); C. Lineau (Rennes); J.F. Muir (Rouen);F. Patte (Poitiers); J.L. Pujol (Montpellier); J.Y. Rigault (Lorient); E. Tuchais (Angers). They also thank I. Brohet for secretarial assistance and preparation of the manuscript.

\section{References}

1. Pinkerton $\mathrm{H}$. The reaction to oils and fats in the lung. Arch Pathol 1928; 5: 380-401.

2. Ikeda K. Lipoid pneumonia of the adult type. Arch Pathol 1937; 23: 470-492.

3. Kaplan L. Combined cod liver oil and liquid petrolatum pneumonia in a child. Am J Dis Child 1941; 62: 1217-1223.

4. Spickard A, Hirschmann JV. Exogenous lipoid pneumonia. Arch Intern Med 1994; 154: 686-692.

5. Woodhead M, Parkes WR. Disorders caused by other organic agents: oil granuloma (lipoid pneumonia). In: Parkes WR, ed. Occupational Lung Disorders. Oxford, Butterworth-Heinemann Ltd, 1994; pp. 778-782.

6. Genereux GP. Lipids in the lung: radiologic-pathologic correlation. J Can Assoc Radiol 1970; 21: 2-15.

7. Rouffy J, Almosni M, Chelloul N, et al. Aspects actuels des lipoidoses pulmonaires exogènes de l'adulte. Ann Med Interne 1976; 127: 637-643.

8. Frija J. Semantique des pneumopathies infiltrantes diffuses étudiées par la tomodensitométrie. Rev Im Med 1991; 3: 355-361.

9. Tuddenham WJ. Glossary of term for thoracic radiology: recommendations of the nomenclature committee of the Fleischner Society. AJR 1984; 143: 509-517.

10. Volk BW, Nathanson L, Losner S, Slade WR, Jacobi M. Incidence of lipoid pneumonia in a survey of 389 chronically ill patients. Am J Med 1951; 10: 316-324.

11. Even R, Lecoeur J, Sors C. Les pneumopathies huileuses de l'adulte. Sem Hôp Paris 1948; 24: 1387-1394.

12. Losner S, Volk BW, Slade WR, Nathanson L, Jacobi M. Diagnosis of lipoid pneumonia by examination of sputum. Am J Clin Pathol 1950; 20: 539-545.

13. Wright BA, Jeffrey PH. Lipoid pneumonia. Semin Respir Infect 1990; 5: 314-321.

14. Genevrier R, Daussy M, Baveria E, Gacouin JC. Les pneumopathies huileuses de l'adulte: à propos d'une observation à forme pseudo-tumorale. Sem Hôp Paris 1972; 48: 2607-2614.

15. Sodeman WA, Stuart BM. Lipoid pneumonia in adults. Ann Intern Med 1946; 24: 241-253.

16. Weiler J, Roussel G. Les pneumopathies lipidiques. France Med 1963; 26: 5-27.

17. Wheeler PS, Stitik FP, Hutchins GM, Klinefelter HF, Siegelman SS. Diagnosis of lipoid pneumonia by computed tomography. JAMA 1981; 245: 65-66.

18. Joshi RR, Cholankeril JV. Computed tomography in lipoid pneumonia. J Comput Assist Tomogr 1985; 9: 211-213.

19. Brechot JM, Buy JN, Laaban JP, Rochemaure J. Computed 
tomography and magnetic resonance findings in lipoid pneumonia. Thorax 1991; 46: 738-739.

20. Im JGG, Han MC, Yu EJ, et al. Lobar bronchioloalveolar carcinoma: angiogram sign on CT scans. Radiology 1990; 176: 749-753.

21. Corwin RW, Irwin RS. The lipids laden alveolar macrophages as a marker of aspiration in parenchymal lung disease. Am Rev Respir Dis 1985; 132: 576-581.

22. Lauque D, Dongay G, Levadet T, Caratero C, Carles P. Bronchoalveolar lavage in liquid paraffin pneumonitis. Chest 1990; 98: 1149-1155.

23. Breton JL, Ranfaing E, Clement F, Faure E. Pneumopathie lipidique exogène d'origine professionnelle. Presse Méd 1990; 19: 1724.

24. Le Bon B, Praet JP, Mostin M, Chami Y, Sergysels R.
Pneumopathie secondaire à l'utilisation abusive de spray dépoussiérant. Rev Mal Respir 1992; 9: 213-215.

25. Perol M, Vallon C, Vallon JJ, Guerin JC. Pneumopathie lipidique par exposition professionnelle à l'huile de coupe. Rev Mal Respir 1989; 6: 271-274.

26. Ameille J, Le Tinier JY, Reigneau O, Rochemaure J, Proteau J. Exposition professionnelle à l'inhalation de paraffine et pathologie respiratoire. Arch Mal Prof Med Trav Secur Soc 1984; 45: 264-265.

27. Fournier P, Aerts J, Damade R, Pasquier P. Une cause rare de syndrome inflammatoire: la paraffinose pulmonaire. Presse Méd 1990; 19: 1768-1769.

28. Pujol JL, Barneon G, Bousquet J, Michel FB, Godard P. Interstitial pulmonary disease induced by occupational exposure to paraffin. Chest 1990; 97: 234-236. 